\title{
Investigating the spatial scaling effect of the non-linear hydrological response to precipitation forcing in a physically based land surface model
}

\author{
$\mathrm{K} \mathrm{Lee}^{1 *}$ and NS Oh${ }^{2}$ \\ ${ }^{1}$ Korean Water Resources Corporation, 462-1 Jeonnin-dong, Yuseong-gu Daejeon, S. Korea 305-730 \\ ${ }^{2}$ Department of Ocean Civil Engineering, Mokpo National Maritime University, Mokpo, 530-729 S. Korea
}

\begin{abstract}
Precipitation is the most important component and critical to the study of water and energy cycle. In this study we investigated the propagation of precipitation retrieval uncertainty in the simulation of hydrological variables, such as soil moisture, temperature, runoff, and fluxes, for varying spatial resolution on different vegetation cover. Two remotely sensed rain retrievals were explored (one based on satellite IR-only data and the other one based on ground radar data) and three spatial grid resolutions: $0.25^{\circ}, 0.5^{\circ}$ and $1.0^{\circ}$. This investigation was facilitated by an offline Community Land Model (CLM) which is forced by in situ meteorological data from Oklahoma Mesonet and high-resolution $\left(0.1^{\circ} /\right.$ hourly) rain gauge-calibrated WSR-88D radar (Nexrad) based precipitation fields. In turn, radar rainfall is replaced by the satellite rain estimates at coarser resolution $\left(0.25^{\circ}, 0.5^{\circ}\right.$ and 1$)$ to determine their impact on model predictions. A fundamental assumption made in this study is that CLM can adequately represent the physical land surface processes. Results show how uncertainty of precipitation measurement affects the spatial variability of model output in various modelling scales. The study provides some information on the uncertainty of hydrological prediction via interaction between the land surface and near atmosphere fluxes in the modelling approach and hopefully it will contribute to water resource redistribution due to climate change in the Korean Peninsula.
\end{abstract}

Keywords: precipitation, non-linear, remote sensing, CLM

\section{Introduction}

The change and redistribution of water resources due to climate change are of main interest in the hydrological society and the Korean Peninsula is no exception.

Traditionally the long-term climate was regarded as unchanging during the normal lifetime of water resource systems. But significant changes in greenhouse-effect gases and their likely effects on temperature and other climate variables, especially precipitation, have suggested that climate change needs to be considered in water resource planning (Maidment, 1992). The dominant approach was to use a sensitivity analysis and examine the differences according to climate change in a system. A physically based numerical modelling approach has been an alternative to studying the effect of climate change on the regional and global water resource budget.

Land surface-atmosphere interaction processes such as evaporation from bare soil or from soil beneath vegetation, infiltration into the soil, and surface runoff are important aspects for weather/climate forecasting and these features are controlled by surface variables such as soil moisture and temperature, soil texture, biomass, surface roughness, and, most importantly, meteorological condition. Precipitation as a driving force is arguably the most important component of the land-vegetation-atmosphere system accountable for shaping the state of the climate and variability of water in the hydrological cycle. Thus, correct precipitation estimation is crucial in the land-atmosphere

\footnotetext{
* To whom all correspondence should be addressed. 용 +82 42860 0348; fax: +82 428600349 ; e-mail:klee@kowaco.or.kr

Received 21 January 2005; accepted in revised form 19 October 2005.
}

interaction. There have been some attempts to predict temporal and spatial variation of precipitation using a physically based atmospheric modelling approach but it is unfortunate that the atmospheric modelling approach is not satisfactory. Quantitative precipitation information is important in the evaluation of the simulation data and/or initialisation and/or assimilation of the land surface and atmospheric modelling approach. However, the existing quantitative precipitation information is scarce, which leads to frustration for the hydrologist and atmospheric scientist. Recently, the remote sensing technique is being seen as a promising tool for large-scale precipitation observation and studies have been successfully conducted in this field. This technique is especially promising for undeveloped countries where there have not been many observations.

In general there are several factors that affect the modelling results (Arnaud et al, 2002), namely the physical structure of the model; the model parameters; the numerical resolution; and the accuracy of input data. The choice of the precipitation retrieval data to be used is the first step in land-surface simulation study and the choice is often made on a largely subjective and intuitive basis.

The impact of precipitation retrieval error on the simulation of hydrological variables (hereafter called error propagation) has been the subject of a number of studies (Sharif et al., 2002; Borga et al., 2000). These studies by Borga et al. and Sharif et al. focused on error propagation in runoff prediction driven by radar rainfall observations. Guo et al. (2004) intensively investigated the spatial variability of the radar-based precipitation measurement and showed the impacts of the different precipitation sources (radar- and ground-based measurement) based on the modelling approach. Yu et al. (1999) simulated streamflow with a model-derived and observed precipitation and they 
concluded that the simulated streamflow with the model-derived precipitation is lower than that with observed precipitation. Most of the aforementioned studies have focused on the effect of remotely sensed precipitation sampling error on the simulation of hydrological variables.

It is also noted that a given storm may produce different hydrological outputs depending on the choice of the numerical design such as spatial and temporal resolution. Accordingly, another critical aspect when using precipitation data in land surface models is the need to resolve the precipitation variability at high spatial and temporal scale. These factors may have a large influence on the water and energy budget. Lee and Anagnostou (2004) recently investigated the non-linear hydrological response to precipitation forcing with emphasis on the temporal scaling in physically based land surface modelling. They showed that the temporal pattern of precipitation observations is noticeably different in the different remote sensing observations and the responses of hydrological variables to different input precipitation are non-linearly dependent on the pattern of precipitation. Some of the studies on error propagation are based on the numerical modelling experiment where the precipitation input is simulated according to some error distribution characterising the sensor retrieval uncertainty. However, not much work has been done on understanding the effect of the retrieval uncertainty using actual remote sensing data (Lee and Anagnostou, 2004). Also many studies have been confined to investigating the surface precipitation-runoff relations.

In this study we investigate the non-linear effect of precipitation retrieval on the simulation of land surface hydrological parameters and its dependence on spatial scales. We compare the prognostic hydrological output forced by the precipitation estimate from two typical remote sensing platforms (i.e., ground radar and geo-stationary satellite IR) with coincident gridaveraged rainfall data measured by a dense cluster of gauges. We evaluate difference statistics (in terms of rainfall and the various simulated land surface parameters) between the remote sensing IR rainfall retrievals and grid-averaged radar rainfall (considered as a reference in this study).

\section{Land surface model}

On the basis of externally forcing data (precipitation, radiation, wind speed, air temperature, and humidity) the land surface model generally computes a number of prognostic variables that include runoff, soil moisture, temperature in the soil layer, water intercepted on the canopy, leaf temperature, latent heat flux, and sensible heat flux. The ancillary soil and vegetation data, used to specify the nature and characteristics of the surface cover, are mostly given as prescribed input data. The Community Land Model (CLM-Version 2) chosen in this study is a one-dimensional land surface model developed and supported by a diverse group of scientists. It is freely available to the research community. CLM is based on the Bonan (1996) land surface model, which was modified to incorporate the best features of BATS (biosphere-atmosphere transfer scheme) (Dickinson et al., 1986) and the IAP94 land surface model (Dai and Zeng, 1997). The soil and vegetation data, used to specify the nature and characteristics of the surface cover, are mostly derived from space-borne remote sensing observations. CLM has one vegetation layer as in most land surface models, 10 unevenly spaced vertical soil layers with variable hydraulic conductivity, and up to 5 snow layers depending on the total snow depth. The surface grid cell can be subdivided into a number of tiles that consist of a single type of land cover; the model performs the water and energy
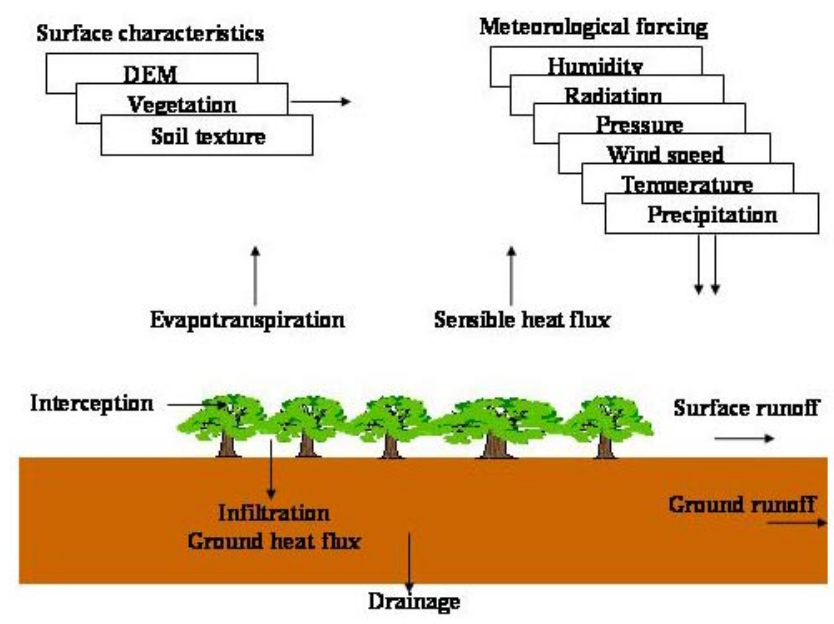

Figure 1

General hydrological processes for CLM

balance calculations over each tile at every time step. Most surface processes such as evaporation from the ground, transpiration from the plants' rooting zone, soil and snow water propagation, leaf temperature and fluxes, soil and snow temperature, and phase change are parameterised through physical-empirical equations. The parameterisation of runoff-related processes is based on the TOPMODEL concept (Beven and Kirkby, 1979). General hydrological processes for CLM are shown in Fig. 1.

\section{Study region and field data}

The study region covers two $1^{\circ}$ grid areas in Oklahoma associated with distinct vegetation cover. The latitude/longitude centres of the sparsely vegetated (hereafter called HOLL) and highly vegetated (hereafter called SALL) $1^{\circ}$ sites are $34.6861 \mathrm{~N} / 99.8339 \mathrm{~W}$ and $35.4360 \mathrm{~N} / 94.7740 \mathrm{~W}$, respectively. The sites include five and three MESONET stations, respectively. The dominant vegetation types for both study sites are non-arctic grass (Type 13 in CLM) and broadleaf deciduous temperate trees (Type 7 in CLM), respectively. The soil textures for HOLL (SALL) are sand and clay at $47 \%(54 \%)$ and $19 \%(23 \%)$ coverage, respectively. The average leaf area index (LAI) for HOLL and SALL in June is 1.3 and 5.3, respectively.

As mentioned earlier, two types of data are generally needed to run a land surface scheme: land surface characteristics and meteorological forcing data. In CLM, the land surface data include vegetation cover type, vegetation fraction, monthly leaf and stem area index, canopy top and bottom heights, and soil texture and colour. Those data are available at $1 \mathrm{~km}$ spatial resolution and mostly derived from space-borne remote sensing observations such as the IGBP DISCover dataset (Loveland et al., 2000), University of Maryland tree cover dataset (DeFries et al., 2000), advanced very high resolution radiometer (AVHRR) (Bonan et al., 2002), and IGBP soil dataset (Global Soil Data Task, 2000). The meteorological forcing data include grid-averaged values of meteorological measurements from the MESONET stations (Brock et al., 1995; Elliot et al., 1994); and radar (Nexrad) and satellite IR-based rainfall retrievals.

The radar rainfall fields are extracted from the National Radar Rainfall Mosaic available at the Hydrologic Rainfall Analysis Product (HRAP) $\sim 4-\mathrm{km}$ resolution (Fulton et al., 1998). The IR rain retrieval is part of a variable rainfall product (VAR) array produced in real-time at NASA Goddard Space 

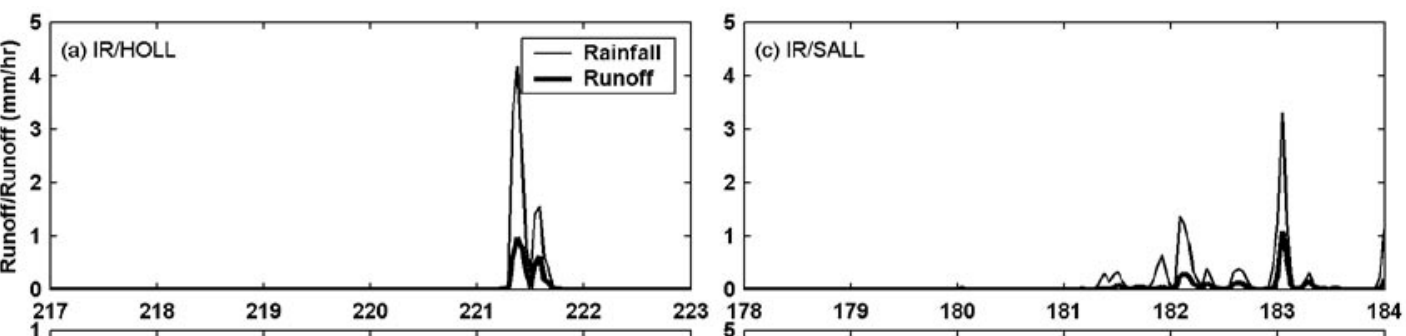

Figure 2

Rain rates and

the corresponding runoff simulated

by CLM of Nexrad and IR measurements for sample periods at HOLL (left panels) and SALL (right panels) sites
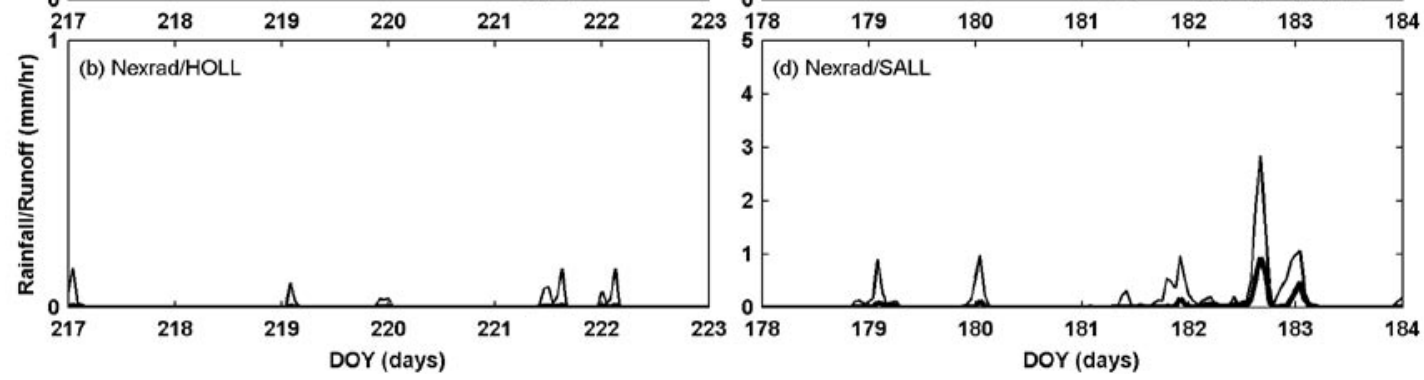

Flight Center by Huffman et al. (2001). IR retrieval is derived from the brightness temperature, which is monitored at the top of cloud cover. Hence, the brightness temperature tends to include stronger information on regional convection storm and surface rainfall rate over highly vegetated areas. It is based on an IR rain algorithm applied to the NOAA Climate Prediction Center $1 / 2$-hourly global infrared composites (Janowiak et al., 2000). Rain rates are then aggregated to $0.25^{\circ}$ spatial grid resolution and hourly accumulations. The IR algorithm is calibrated dynamically (on a month-to-month basis) on the basis of common datasets of $1 / 2$-hourly IR brightness temperature and instantaneous precipitation fields, derived from low-orbit passive microwave observations (TRMM, SSM/I), matched at $5 \%$ monthly space-time windows. The calibration is based on matching the probability density histograms of IR brightness temperatures and MW rain rates falling within a common dataset (Huffman et al., 2001).

\section{Numerical experiment}

The CLM simulates the one-dimensional grid average values at two distinct vegetation cover sites for the year of 2002 (1 Jan to $31 \mathrm{Dec}$ ). The initial soil moisture condition was fixed at the medium level $(0.15)$ and the initial soil temperature is reasonably chosen as $273 \mathrm{~K}$. The time step for the simulation was $1 \mathrm{~h}$ and 5 min Mesonet (Brock et al., 1995; Elliot et al., 1994) and forcing data were hourly aggregated for the simulation. Two model experiments performed in the study were forced with different rainfall input datasets (grid-averaged Nexrad (Radar) and IR). During the spin-up (1 Jan to 31 May), the grid-averaged rain gauge rainfall (Brock et al., 1995; Elliot et al., 1994) was used as a rainfall forcing. Consequently, the only forcing data that would differentiate the prognostic land surface variables between the two simulation experiments is the different source of precipitation input. The simulation was then performed at three different resolutions $\left(0.25^{\circ}, 0.5^{\circ}\right.$ and $\left.1^{\circ}\right)$ to determine their impact on model predictions. The prognostic variables forced by spatially distributed rainfall data at three different resolutions were aggregated to $1^{\circ}$ representative values and compared. Only the output for the warm season is used for analysis.

The land surface variables evaluated here are: latent heat flux (LE), sensible heat flux (SH), surface runoff (Roff), soil moisture content at 1 and $20 \mathrm{~cm}$ depth $\left(\theta_{S}\right)$, and soil temperature at 1 and $20 \mathrm{~cm}$ depth $\left(\theta_{T}\right)$.

\begin{tabular}{|l|l|l|l|l|}
\hline \multicolumn{5}{|c|}{ TABLE 1 } \\
\multicolumn{3}{|c|}{$\begin{array}{l}\text { Statistics of hourly precipitation and sensor } \\
\text { retrieval error (10 grid-averaged value for the } \\
\text { period May to Oct 2002) for both sites }\end{array}$} \\
\hline \multicolumn{3}{|c|}{ HOLL } & \multicolumn{2}{c|}{ SALL } \\
\hline & $\begin{array}{l}\text { Mean } \\
\text { (mm/h) }\end{array}$ & $\begin{array}{l}\text { Relative error, } \\
\text { mean (STD) } \\
\text { (in \%) }\end{array}$ & $\begin{array}{l}\text { Mean } \\
\text { (mm/h) }\end{array}$ & $\begin{array}{l}\text { Relative } \\
\text { error, } \\
\text { mean } \\
\text { (STD) } \\
\text { (in \%) }\end{array}$ \\
\hline IR & 0.1367 & $60(130)$ & 0.1210 & $-12(76)$ \\
\hline Nexrad & 0.0856 &. & 0.1380 &. \\
\hline
\end{tabular}

\section{Results and discussion}

First, Fig. 2 shows the grid-averaged rainfall $\left(1^{\circ}\right)$ measured by the two sensors and the simulated runoff at the two selected sites. There are noticeable differences in the magnitude and temporal pattern of rain rates between the two sensors, especially DOY 221 in HOLL and DOY 183. Table 1 summarises the statistics of sensor retrieval error (unconditional mean rainfall and relative error). Figure 3 shows a scatter plot of radar and IR vs. groundbased gauge observations for the two study sites. More missing events are found in IR retrieval. In Fig. 4, the cumulative distribution function (CDF) as a function of the rainfall rate is shown. The CDF of a random variable $\mathbf{X}$ can be denoted by $\mathrm{F}(\mathrm{x})$, defined as:

$$
F(x)=\operatorname{Pr}(\mathbf{X} \leq x)
$$

Both radar and IR seem to overestimate low rain rates and underestimate high rain rates of the ground-based rainfall in terms of frequency (low slope). These phenomena are more pronounced in highly vegetated cover (SALL) but both radar and IR data have similar rainfall rate distributions. Next we looked at categorical statistics, which is a schematic measurement tool for the correspondence between the reference and estimation (Ebert and McBride, 2002). The probability of detection (POD) measures the success of the forecast in correctly predicting the occurrence of rain. For example, $\mathrm{POD}=1$ means a perfect score:

$$
P O D=n 1 /(n 1+n 3)
$$

The counts $n 1$ and $n 3$ indicate the total number of hits and misses, respectively. The POD is calculated from the $2 \times 2$ contingency table (see Table 2) for a range of the threshold values, 

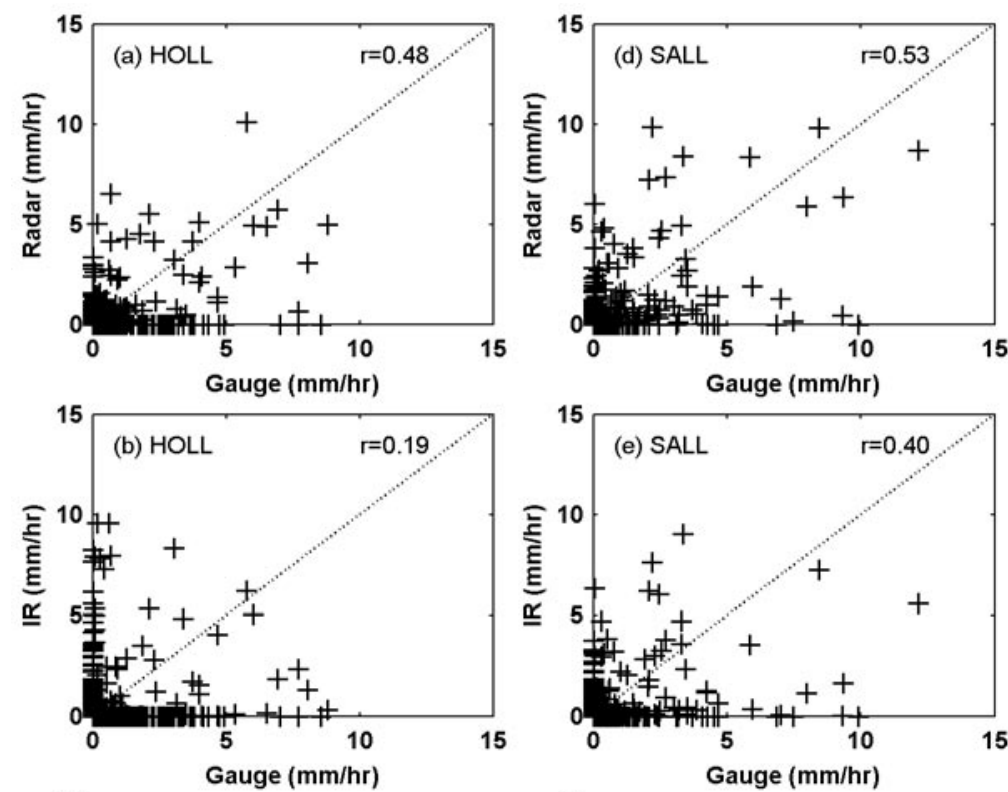

Figure 3 (left)

Scatter plot of rainfall rate of gauge vs.radar ( $a$ and $c$ ) and gauge vs. IR ( $b$ and $d)$ for HOLL (a and $b$ ) and SALL (c and d)

Figure 4 (bottom)

$C D F$ of gauge, radar, and IR based measurement for HOLL (a) and SALL (b)
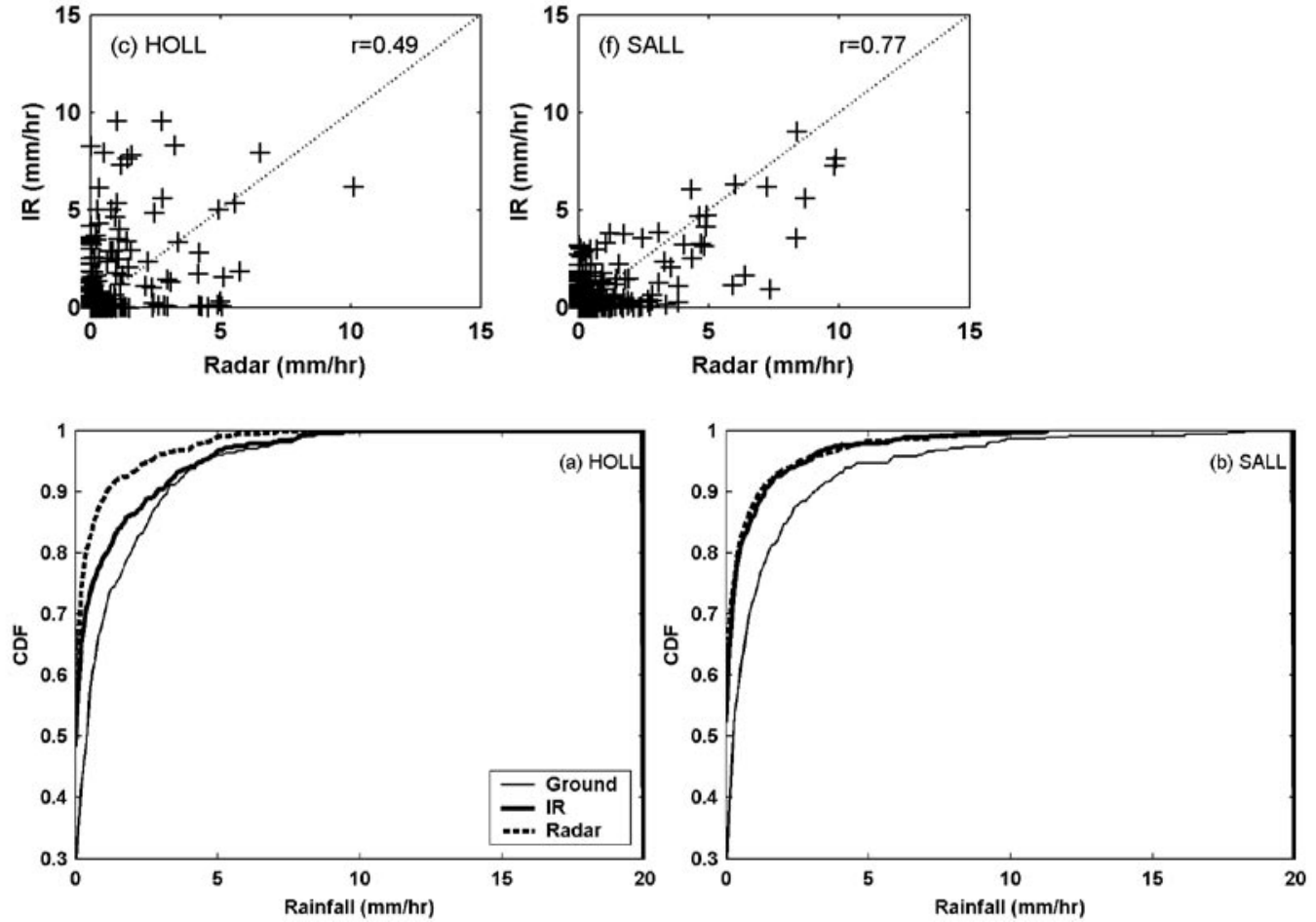

TABLE 2

Contingency table. The counts n1, n2, n3, and n4 indicate the total number of hits, false alarms, misses and correct rejections. $n=n 1+n 2+n 3+n 4$, and the "obs:, "ref", and "thr" denotes observation, reference, and threshold rainfall rate, respectively.

\begin{tabular}{|l|c|c|}
\hline & $\boldsymbol{P}_{\text {ref }}>\boldsymbol{t h} \boldsymbol{r}$ & $\boldsymbol{P}_{\text {ref }} \leq \boldsymbol{t h} \boldsymbol{r}$ \\
\hline$P_{\text {obs }}>t h r$ & $\mathrm{n} 1$ & $\mathrm{n} 2$ \\
\hline$P_{\text {obs }} \leq t h r$ & $\mathrm{n} 3$ & $\mathrm{n} 4$ \\
\hline
\end{tabular}

and the POD analysis result is shown in Table 3.

Clearly, the IR rainfall is larger for the sparsely vegetated area and slightly smaller for the highly vegetated area. The relative error standard deviation (standard error) is larger for the HOLL site. It is noted that the structure of error strongly depends on the

sensor calibration to a certain extent and the calibration effect of Z-R relation might vary with the rainfall intensity, which is not considered in this study. Next CLM simulations for three different resolutions $\left(0.25^{\circ}, 0.50^{\circ}\right.$, and $\left.1.0^{\circ}\right)$ were performed at two study sites. The specification of the model parameter is a common issue in the land surface modelling approach and the model results are strongly dependent on these model parameters. The model parameters of Version 2.0 CLM (Bonan et al., 2002) to specify the structure of the model physics and surface characteristics are used without any modification. Tables 4 and 5 summarise the mean and standard deviation (IR retrieval) of the relative error (Nexrad as a reference) for each of the hydrological variables for the period of May to Oct 2002. We note differences between the two vegetation sites on both the systematic and random error propagation. In sparse vegetation (HOLL) the systematic error decreases from rainfall to land surface param- 


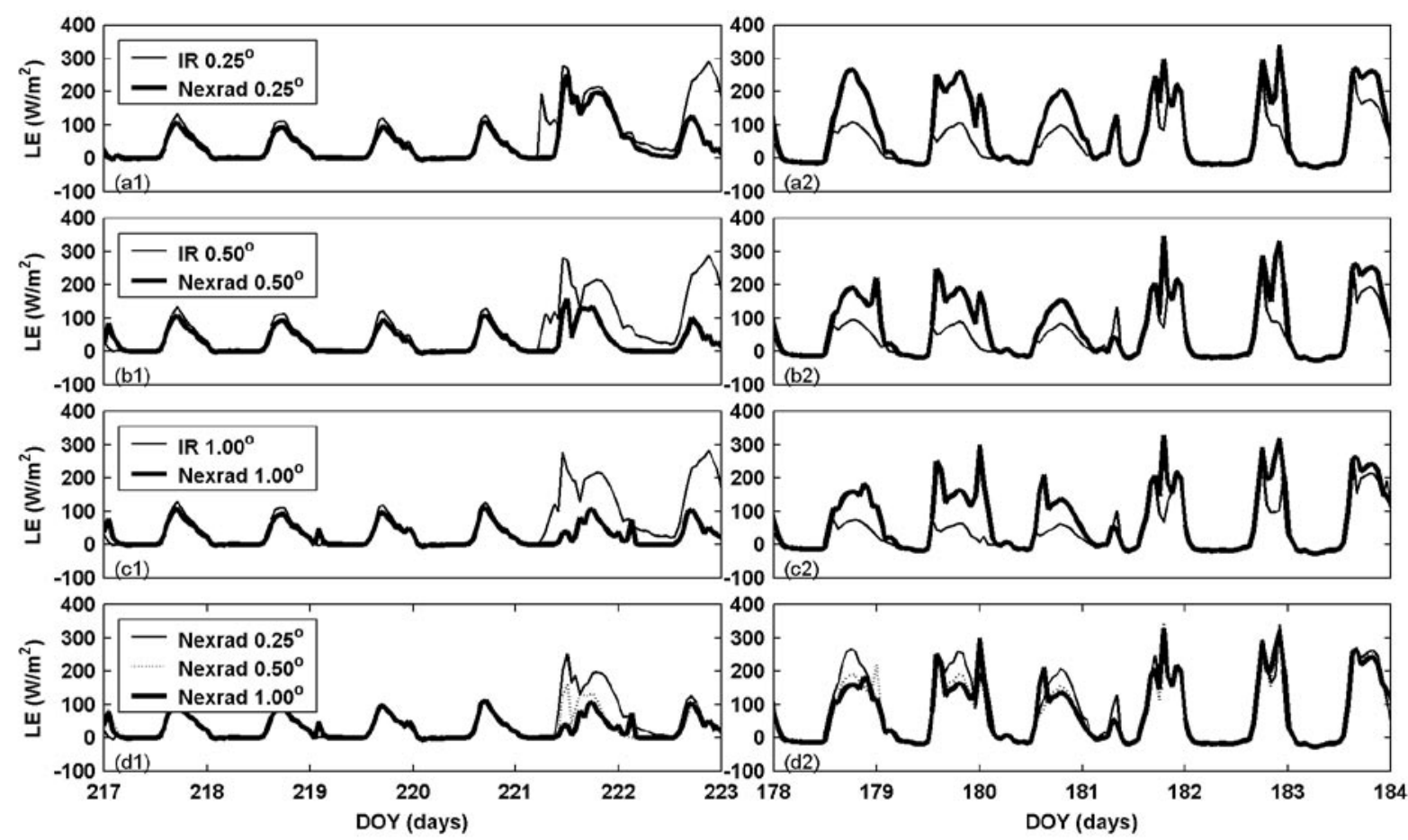

Figure 5

Latent heat flux (LE) simulated by CLM for three different resolutions $\left(0.25^{\circ}, 0.50^{\circ}\right.$, and $\left.1.0^{\circ}\right)$ at $H O L L$ (left panels) and SALL (right panels) sites

\begin{tabular}{|c|c|c|c|c|}
\hline \multicolumn{5}{|c|}{ TABLE 3 } \\
$\begin{array}{c}\text { POD of radar and IR rain estimates pre- } \\
\text { sented for different rain-rate thresholds }\end{array}$ \\
\hline \multicolumn{2}{|c|}{ HOLL } & \multicolumn{2}{c|}{ SALL } \\
\hline $\begin{array}{c}\text { Rain rate } \\
\text { threshold } \\
\text { (mm/h) }\end{array}$ & IR & Radar & IR & Radar \\
\hline 0 & 0.36 & 0.49 & 0.46 & 0.59 \\
\hline 1 & 0.21 & 0.25 & 0.31 & 0.44 \\
\hline 2 & 0.16 & 0.27 & 0.31 & 0.37 \\
\hline 3 & 0.18 & 0.26 & 0.26 & 0.33 \\
\hline 4 & 0.14 & 0.29 & 0.18 & 0.32 \\
\hline 5 & 0.17 & 0.25 & 0.20 & 0.30 \\
\hline 6 & 0 & 0.10 & 0.12 & 0.19 \\
\hline 7 & 0 & 0.14 & 0.13 & 0.13 \\
\hline 8 & 0 & 0 & 0.09 & 0.18 \\
\hline 9 & 0 & 0 & 0.10 & 0 \\
\hline 10 & 0 & 0 & 0.20 & 0 \\
\hline
\end{tabular}

eters with the exception of runoff. Runoff error magnifies by $\sim 2$ times for the HOLL site. The sensible heat flux (latent heat flux) is underestimated (overestimated) at HOLL, while moderately overestimated (underestimated) at SALL. The rainfall is overestimated at HOLL and underestimated at SALL and it is believed that the behaviour of the surface flux error is due to the trend of rainfall estimation because the temperature significantly varies with rain/no rain. On the basis of these results, there is, however, little evidence that the systematic error is significant depending on the spatial resolution over the study period. But the difference of the random error is noticeable, especially, in the runoff at HOLL as seen in Table 5.

\begin{tabular}{|c|c|c|c|c|}
\hline \multicolumn{5}{|c|}{$\begin{array}{c}\text { TABLE } 4 \\
\text { Mean of the relative error (in \%) of hydro- } \\
\text { logical variables derived based on hourly } \\
\text { IR rainfall input; the Nexrad rainfall was } \\
\text { used to derive the reference } \\
\text { hydrological variables }\end{array}$} \\
\hline & & $0.25^{\circ}$ & $0.50^{\circ}$ & $1.00^{\circ}$ \\
\hline \multirow[t]{8}{*}{ HOLL } & $\mathrm{P}$ & 59.7 & 59.7 & 59.7 \\
\hline & LE & 34.3 & 31.2 & 31.6 \\
\hline & $\mathrm{SH}$ & -25.9 & -25.1 & -27.4 \\
\hline & Roff & 114.8 & 115.1 & 115.8 \\
\hline & $\theta_{s}(1 \mathrm{~cm})$ & 21.3 & 19.7 & 21.2 \\
\hline & $\theta_{s}(20 \mathrm{~cm})$ & 7.4 & 7.3 & 8.3 \\
\hline & $\theta_{s}(1 \mathrm{~cm})$ & -0.5 & -0.5 & -0.5 \\
\hline & $\theta_{s}(20 \mathrm{~cm})$ & -0.5 & -0.4 & -0.4 \\
\hline \multirow[t]{8}{*}{$\begin{array}{l}\text { SALL } \\
\end{array}$} & $\mathrm{P}$ & -12.3 & -12.3 & -12.3 \\
\hline & LE & -10.5 & -12.1 & -13.7 \\
\hline & $\mathrm{SH}$ & 12.9 & 15.2 & 17.0 \\
\hline & Roff & -7.4 & -6.7 & -6.4 \\
\hline & $\theta_{s}(1 \mathrm{~cm})$ & -8.1 & -8.3 & -8.1 \\
\hline & $\theta_{s}(20 \mathrm{~cm})$ & -5.4 & -5.2 & -4.7 \\
\hline & $\theta_{s}(1 \mathrm{~cm})$ & 0.03 & 0.03 & 0.06 \\
\hline & $\theta(20 \mathrm{~cm})$ & 0.02 & 0.02 & 0.05 \\
\hline
\end{tabular}

The systematic error of near surface soil moisture $(1 \mathrm{~cm})$ is larger than that of deep soil moisture $(20 \mathrm{~cm})$, while the random error of deep soil moisture is larger at the HOLL site. The error propagation of soil temperature is slight, especially, in the systematic error and nearly in the order of the sensible heat flux.

Figures 5 to 7 show examples of several days of simulated hydrological variables using two different rainfall retrievals as forcing data. It is obvious that there are significant differences in hydrological variables depending on the spatial resolution at rainfall event, even though the overall values for the study 


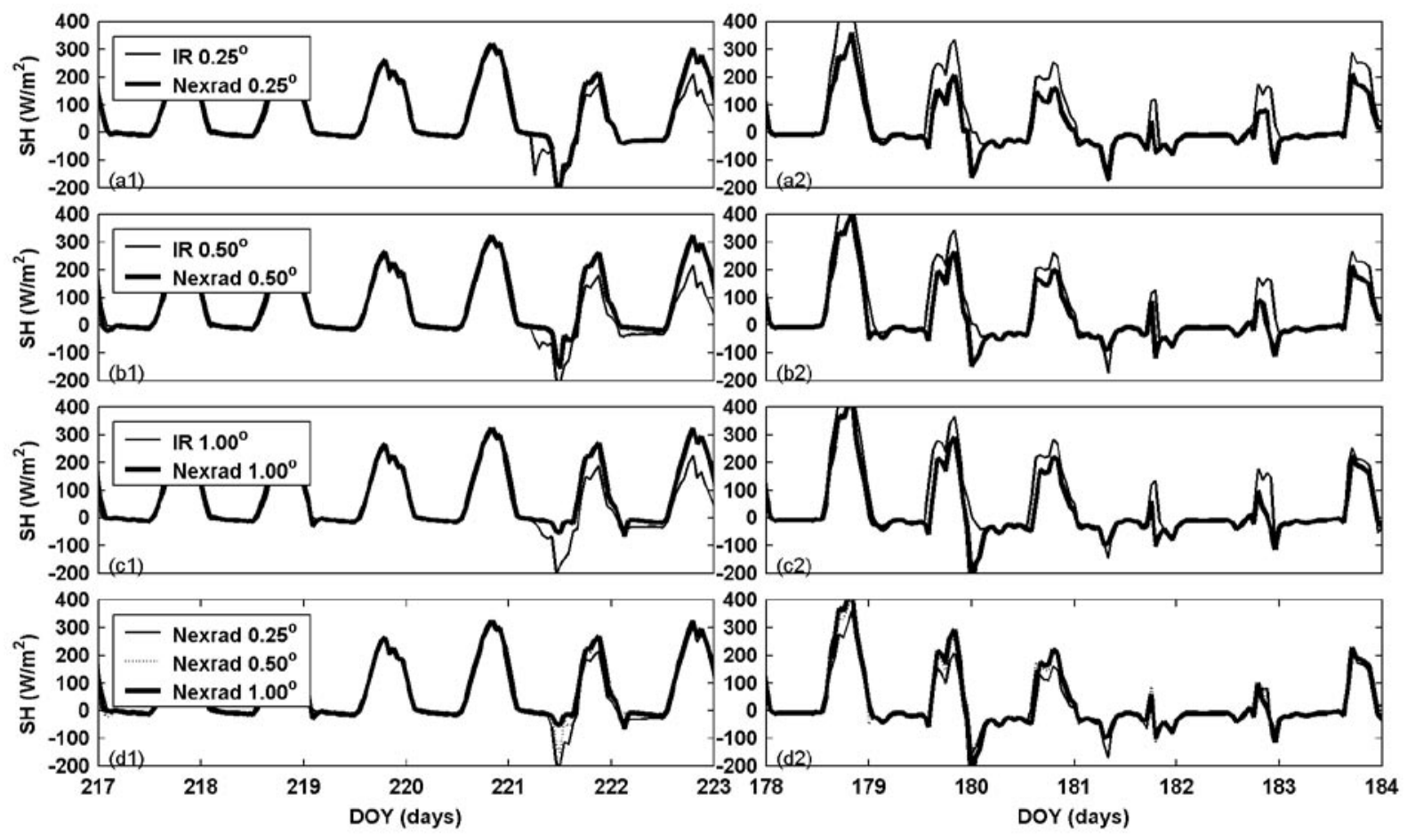

Figure 6

Rain rates and the corresponding runoff simulated by CLM of Nexrad and IR measurements for sensible heat flux (SH)

\begin{tabular}{|c|c|c|c|c|}
\hline \multicolumn{5}{|c|}{$\begin{array}{c}\text { TABLE } 5 \\
\text { Standard deviation (STD) of the relative error } \\
\text { (in \%) of hydrological variables derived based on } \\
\text { hourly IR rainfall input; the Nexrad rainfall was } \\
\text { used to derive the reference hydrological variables }\end{array}$} \\
\hline & & $0.25^{\circ}$ & $0.50^{\circ}$ & $1.00^{\circ}$ \\
\hline \multirow[t]{8}{*}{ HOLL } & $\mathrm{P}$ & 123.8 & 129.2 & 130.3 \\
\hline & LE & 76.2 & 73.6 & 68.0 \\
\hline & $\mathrm{SH}$ & 34.5 & 33.9 & 32.0 \\
\hline & Roff & 187.0 & 213.4 & 231.5 \\
\hline & $\theta_{s}(1 \mathrm{~cm})$ & 98.6 & 95.1 & 88.0 \\
\hline & $\theta_{s}(20 \mathrm{~cm})$ & 112.6 & 107.5 & 117.1 \\
\hline & $\theta_{T}(1 \mathrm{~cm})$ & 37.8 & 36.7 & 33.8 \\
\hline & $\theta_{T}(20 \mathrm{~cm})$ & 39.8 & 38.8 & 35.5 \\
\hline \multirow[t]{8}{*}{ SALL } & $\mathrm{P}$ & 93.0 & 88.0 & 76.1 \\
\hline & $\mathrm{LE}$ & 48.9 & 48.5 & 47.0 \\
\hline & $\mathrm{SH}$ & 29.0 & 28.9 & 27.2 \\
\hline & Roff & 93.2 & 91.3 & 91.5 \\
\hline & $\theta_{s}(1 \mathrm{~cm})$ & 86.7 & 83.0 & 78.4 \\
\hline & $\theta_{s}(20 \mathrm{~cm})$ & 70.6 & 63.3 & 60.4 \\
\hline & $\theta_{T}(1 \mathrm{~cm})$ & 19.7 & 19.0 & 16.7 \\
\hline & $(20 \mathrm{~cm})$ & 15.1 & 14.6 & 12.8 \\
\hline
\end{tabular}

period (Table 4) are not noticeably different depending on the spatial resolution. The significant differences are shown with the spatial resolution in the surface flux at a low rainfall rate (Fig. 5(d1), (d2) and Fig. 5(d1), (d2), while the differences are shown in the soil moisture content at a high rainfall rate (Fig.7(d2)

It is of interest to see how the hydrological variables are correlated both spatially and temporally. Figure 7 shows the correlation coefficient as a function of the distance for two vegetation sites. There is a tendency in the correlation length to be greater for the sparsely vegetated area and IR retrieval rainfall. The correlation of the runoff is similar to that of precipitation, which is expected being the most direct outcome of precipitation. There is some suggestion that the land surface fluxes are spatially more correlated than runoff.

Next, the results show how much memory remains in the error propagation from precipitation to the land surface parameters for three resolutions. The cross-correlation coefficient, $\rho$, for each prognostic variable, was calculated as follows:

$$
\rho_{k}=\frac{\sigma_{v, p}(k)}{\sigma_{V} \sigma_{p}}
$$

where:

$\sigma_{V \cdot P}$ is a covariance between the error in a prognostic variable, $V$, and corresponding error in precipitation, $P$, for a time lag $k$ (in hours)

$\sigma_{v}$ and $\sigma_{p}$ are the standard deviations.

Figures 9-10 show the results of the lag cross-correlation values presented as function of time lag. The most noticeable and significant result demonstrated by Figs. 9 to 10 is that the coarser resolution $\left(1.0^{\circ}\right)$ has longer memory and the runoff is highly correlated to precipitation but approaches the equilibrium as quickly as expected.

The IR retrieval has a longer memory between two sources of precipitation and this can be attributed to high variance of the retrieval. It is also found that the correlation of the surface fluxes is very low but the memory remains longer than runoff. As mentioned earlier, the temperature is low on rainy days and then the latent heat flux is positively correlated but the sensible heat flux is negatively correlated (Figs. 9 (c), (d), (g), and (h)). The propagation of the water movement in the soil media is controlled by the hydraulic conductivity, which is dependent on the soil texture. A typical value for the hydraulic conductivity is 

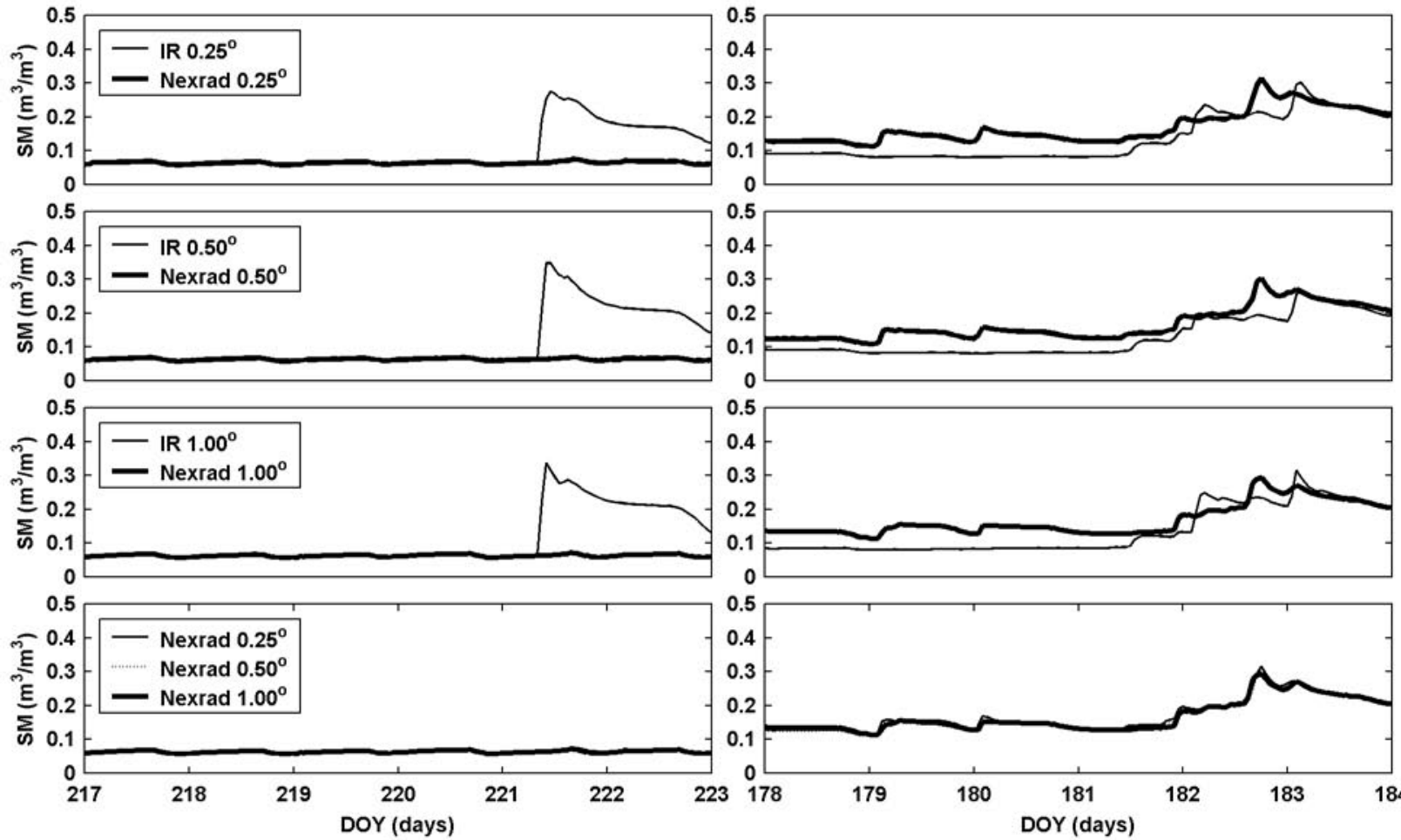

Figure 7

Rain rates and the corresponding runoff simulated by CLM of Nexrad and IR measurements for soil moisture content (SM)
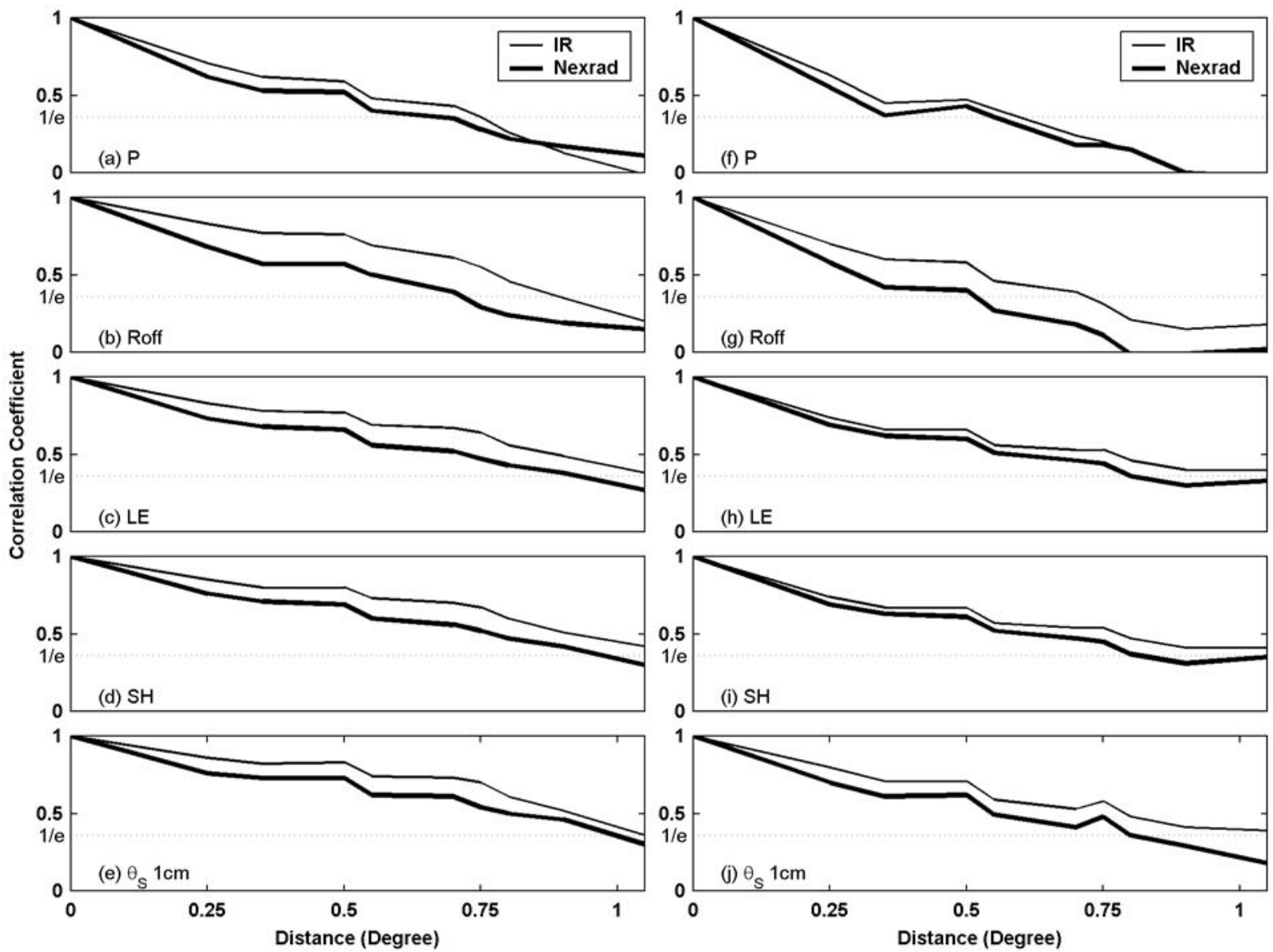

Figure 8

Auto-correlation of Nexrad and IR rain retrieval error for each hydrologic variables at HOLL (left panel) and SALL(right panels) sites 

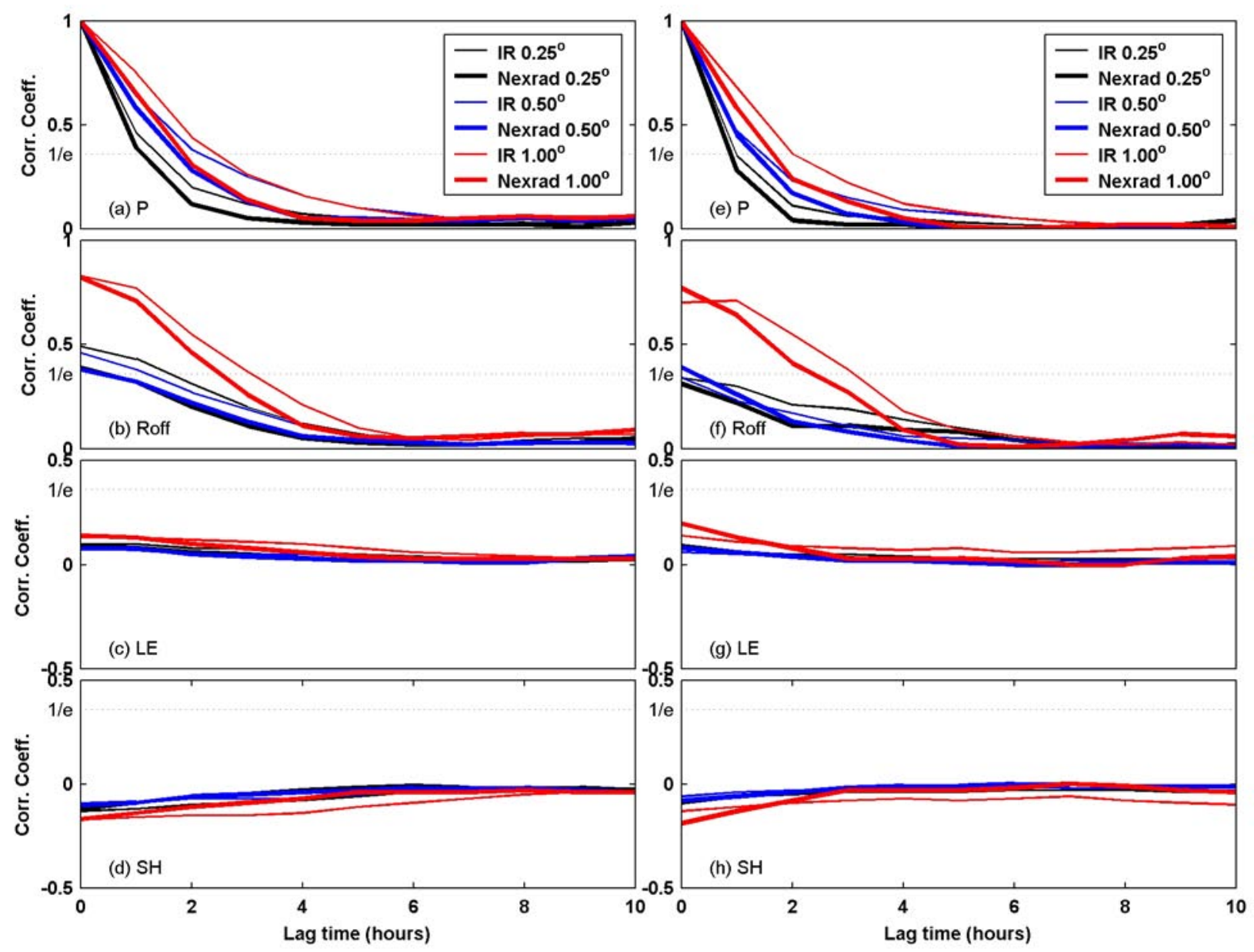

Figure 9

Cross-correlation between precipitation error and the corresponding error in other hydrological variables (runoff, latent heat flux, and sensible heat flux) versus time lag. Left and right panels correspond to HOLL and SALL sites.

$\sim 50 \mathrm{~cm} /$ day and the soil moisture content is not the most direct response to precipitation temporally. The soil moisture error has a lower correlation with the precipitation error (less than 0.5 ) than runoff. But the correlation peaks at around $2 \mathrm{~h}$ time lags for the $1 \mathrm{~cm}$ depths and it is possible for deep soil moisture $(\sim 20 \mathrm{~cm})$ to take tens of hours to reach its peak. The soil temperature has a negligible correlation with precipitation.

\section{Summary and conclusions}

The change in water resources due to climate change is of main interest in the Korean Peninsula. This preliminary study hopefully provides general understanding and some information to hydrologists for the near future.

This study investigated the error propagation of precipitation retrieval to the prediction of land surface parameters associated with different rainfall observations and spatial scales. The strategy adopted is to simulate the prognostic variables at the hourly time step using two different sources of precipitation data (i.e., ground-based Nexrad rainfall and satellite IR rain retrievals), assuming that the model parameters in CLM are well representative of the land surface processes. The simulated land surface parameters using $0.25^{\circ}, 0.5^{\circ}$, and $1.0^{\circ}$ aggregated data for the two remote sensing precipitation observations were compared The primary conclusions of the present study are as follows:
- Temporal patterns of precipitation observations (and consequently its error characteristics) are noticeably different in the two remote sensing observations. The model results show that the responses of hydrological variables (i.e., error propagation) are non-linearly dependent on the pattern of precipitation.

- In sparse vegetation (HOLL) the systematic error decreases from rainfall to land surface parameters with the exception of runoff. The runoff error magnifies by $\sim 2$ times at the HOLL site

- The sensible heat flux (latent heat flux) is underestimated (overestimated) at HOLL, while moderate overestimated (underestimated) at SALL because the rainfall is overestimated at HOLL and underestimated at SALL.

- Over the study period, the systematic error is not significant depending on the spatial resolution but there are significant differences in hydrological variables at rainfall event.

- The coarser resolution $\left(1.0^{\circ}\right)$ has a longer memory and the runoff is highly correlated to precipitation

- The correlation of the soil moisture peaks at around $2 \mathrm{~h}$ time lags for the $1 \mathrm{~cm}$ depths and it takes longer for deep soil moisture to reach its peak

- The soil temperature has negligible correlation with precipitation. 

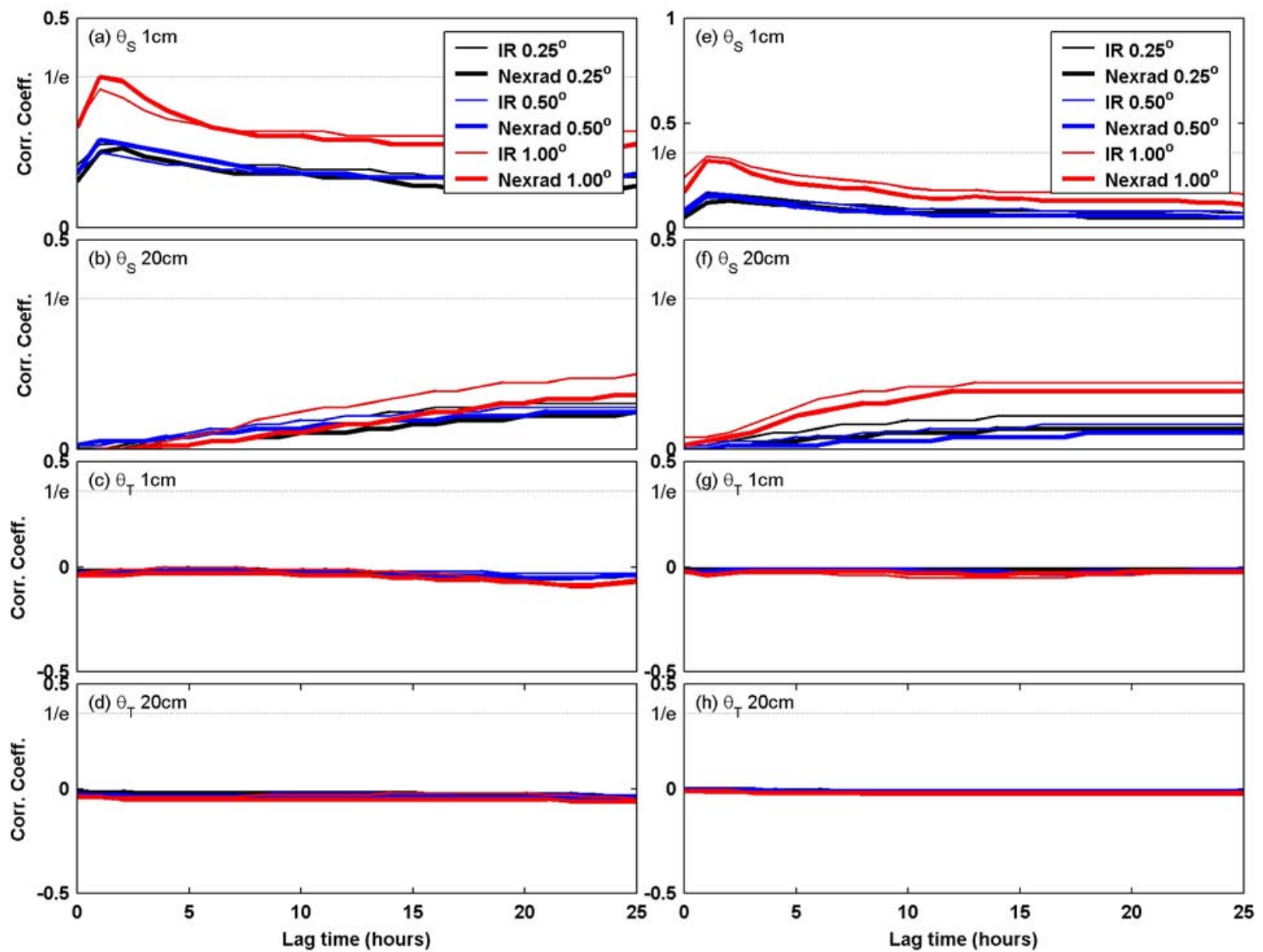

Figure 10

Rain rates and the corresponding runoff simulated by CLM of Nexrad and IR measurements for soil moisture and temperature

Each land surface modelling approach has its own purpose and certain hydrological variables are emphasised. On the basis of the above results, it is recommended that care be taken to choose the precipitation forcing data and spatial resolution in the land surface modelling design. It is hoped that this study will contribute to water resource planning and management in Korean society in the near future by combining the remotely sensed rainfall data and hydrological modelling approaches.

\section{Acknowledgement}

The author would like to thank ORNL Distributed Active Archive Center, Oak Ridge National Laboratory for their cooperation.

\section{References}

ARNAUD P, BOUVIER C, CISNEROS L and DOMINQUEZ R (2002) Influence of rainfall spatial variability on flood prediction. J. Hydrol. 260 (1-4) 216-230.

BEVEN KJ and KIRKBY MJ (1979) A physically based variable contributing area model of basin hydrology. Hydrol. Sci. Bull. 24 (1) 43-69.

BONAN GB, OLSEN KW, VERTENSTEIN M, LEVIS S, ZENG XB, DAI YJ, DICKINSON RE and YANG ZL (2002) The land surface climatology of the community land model coupled to the NCAR community climate model. J. Clim. 15 (22) 3123-3149.
BONAN GB (1996) A land surface model (LSM Version 1.0) for ecological, hydrological, and atmospheric studies: Technical description and user's guide, NCAR Technical Note; NCAR/TN-417+STR, Boulder, CO.

BORGA M, ANAGNOSTOU EN, and FRANK E (2000) On the use of real-time radarrainfall estimates for flood prediction in mountainous basins. J. Geophys. Res. 105 (D2) 2269-2280.

BROCK FV, CRAWFORD KC, ELLIOT RL, CUPERUS GW, STADLER SJ, JOHNSON HJ and EILTS MD (1995) The Oklahoma Mesonet: A technical overview. J. Atmos. Oceanic. Technol. 12 (1) 5-19.

DAI YJ and ZENG QC (1997) A land surface model (IAP94) for climate studies formulation and validation in off-line experiments. Adv. Atmos. Sci. 14 433-460.

DEFRIES RS, HANSEN MC and TOWNSHEND JRC (2000) Continuous fields of vegetation characteristics: a linear mixture model applied to multi-year $8 \mathrm{~km}$ AVHRR data. Int. J. Remote Sensing 21 (6-7) 1389-1414.

DICKINSON RE, HENSERSON-SELLER A, KENNEDY PJ and WILSON MF (1986) Biosphere-Atmosphere Transfer Scheme (BATS) for the NCAR Community Climate Model. Technical Note; NCAR/ TN-275+STR, NCAR, Boulder, CO.

EBERT EE and MCBRIDE JL (2002) Verification of precipitation in weather systems: determination of systematic errors. J. Hydrol. 239 (1-4) 179-202 .

ELLIOT RL, BROCK FV, STONE ML and HARP SL (1994) Configuration decisions for an automated weather station network. Appl. Eng. Agric 10 (1) 45-51.

FULTON RA, BREIDENBACH JP, SEO DJ, MILLER DAand O'BANNON T (1998) The WSR-88D rainfall algorithm. Weather and Forecasting 13 (2) 377-395. 
GLOBAL SOIL DATA TASK (2000) Global soil data products CDROM (IGBP-DIS) International Geosphere-biosphere Programme - Data and Information Available Services (available at http://www daac.ornl.gov.

GUO J, LIANG X and LEUNG RL (2004) Impacts of different precipitation data sources on water budgets. J. Hydrol. 298 (1-4) 311-334.

HUFFMAN GJ, ADLER RF, MORRISEY MM, BOLVIL DT, CURTIS S, JOYCE R, McGAVOCK B and SUSSKIND J (2001) Global precipitation at one degree daily resolution from multisatellite observations. J. Hydrometeorol. 2 (1) 36-60.

JANOWIAK JE, JOYCE RJ and YAROSH Y (2000) A real-time global half-hourly pixel resolution infrared dataset and its applications. Bull. Amer. Meteor. Soc. 82 (2) 205-217.
LEE K and ANAGNOSTOU EN (2004) Investigation of the nonlinear hydrologic response to precipitation forcing in physically based land surface modeling. Can. J. Remote Sensing 30 (5) 706-716.

LOVELAND TR, REED BC, BROWN JF, OHLEN DO, ZHU Z, YANG Land MERCHANT JW (2000) Development of a global land cover characteristics database and IGBP DISCover from $1 \mathrm{~km}$ AVHRR data. Int. J. Remote Sensing 21 (6-7) 1303-1330.

MAIDMENT DR (1992) Handbook of Hydrology. Mcgraw-Hill, Inc.

SHARIF HO, OGDEN FL and KRAJEWISKI WF (2002) Numerical simulations of radar rainfall error propagation. Water Resour. Res. 3 (8) Art. No. 1140.

YU Z, LAKHTAKIA MN, YARNAL B, WHITE RA, MILLER DA and FRANKS B (1999) Simulating the river-basin response to atmospheric forcing by linking a mesoscale meteorological model and hydrologic model. J. Hydrol. 218 (1) 72-91. 